\title{
Detection of Plasmodium falciparum DNA in saliva samples stored at room temperature: potential for a non-invasive saliva-based diagnostic test for malaria
}

Kenji O. Mfuh ${ }^{1,2}$, Samuel Tassi Yunga ${ }^{1,2+}{ }^{2}$, Livo F. Esemu ${ }^{2 \dagger}$, Obase Ngemani Bekindaka², Jessica Yonga ${ }^{2}$, Jean Claude Djontu², Calixt D. Mbakop ${ }^{3}$, Diane W. Taylor ${ }^{1 *}$, Vivek R. Nerurkar ${ }^{1}$ and Rose G. F. Leke ${ }^{2,3}$

\begin{abstract}
Background: Current malaria diagnostic methods require blood collection, that may be associated with pain and the risk of transmitting blood-borne pathogens, and often create poor compliance when repeated sampling is needed. On the other hand, the collection of saliva is minimally invasive; but saliva has not been widely used for the diagnosis of malaria. The aim of this study was to evaluate the diagnostic performance of saliva collected and stored at room temperature using the OMNIgene ${ }^{\circledR}$.ORAL kit for diagnosing Plasmodium falciparum malaria.

Methods: Paired blood and saliva samples were collected from 222 febrile patients in Cameroon. Saliva samples were collected using the OMNIgene ${ }^{\circledR}$.ORAL (OM-501) kit and stored at room temperature for up to 13 months. Thick blood film microscopy (TFM) was used to detect $P$. falciparum blood-stage parasites in blood. Detection of P. falciparum DNA in blood and saliva was based on amplification of the multi-copy $18 \mathrm{~s}$ rRNA gene using the nested-polymerase chain reaction (nPCR).

Results: Prevalence of malaria detected by TFM, nPCR-saliva and nPCR-blood was 22, 29, and 35\%, respectively. Using TFM as the gold standard, the sensitivity of nPCR-saliva and nPCR-blood in detecting P. falciparum was 95 and $100 \%$, respectively; with corresponding specificities of 93 and $87 \%$. When nPCR-blood was used as gold standard, the sensitivity of nPCR-saliva and microscopy was 82 and 68\%, respectively; whereas, the specificity was 99 and 100\%, respectively. Nested PCR-saliva had a very good agreement with both TFM (kappa value 0.8 ) and blood PCR (kappa value 0.8 ). At parasitaemia $>10,000$ parasites/ $\mu$ l of blood, the sensitivity of nPCR-saliva was 100\%. Nested PCR-saliva detected 16 sub-microscopic malaria infections. One year after sample collection, P. falciparum DNA was detected in $80 \%$ of saliva samples stored at room temperature.

Conclusions: Saliva can potentially be used as an alternative non-invasive sample for the diagnosis of malaria and the OMNIgene ${ }^{\circledR}$.ORAL kit is effective at transporting and preserving malaria parasite DNA in saliva at room temperature. The technology described in this study for diagnosis of malaria in resource-limited countries adds on to the armamentarium needed for elimination of malaria.
\end{abstract}

Keywords: Plasmodium falciparum, Malaria, Diagnosis, Saliva, PCR, DNA

\footnotetext{
*Correspondence: dwtaylor@hawaii.edu

'Samuel Tassi Yunga and Livo F. Esemu contributed equally to this work

${ }^{1}$ Department of Tropical Medicine, Medical Microbiology

and Pharmacology, John A. Burns School of Medicine, University

of Hawaii at Manoa, 651 Ilalo Street, Honolulu, HI 96813, USA

Full list of author information is available at the end of the article
} 


\section{Background}

Plasmodium falciparum malaria remains one of the most important infectious diseases in sub-Saharan Africa (SSA). Even with the significant reduction in malaria morbidity and mortality since the beginning of the third millennium, 214 million people (88\% living in SSA) acquired malaria and 438,000 people (90\% from SSA) died from malaria in 2015 [1]. Transmission-blocking interventions, such as insecticide-treated nets, have been hailed as significant contributors to the decrease in the number of malaria cases and deaths. The proportion of children less than 5 years old in SSA who sleep under insecticide-treated nets increased from $<2 \%$ in 2000 to about $68 \%$ in 2015 [1]. However, such gains are threatened by the emergence of drug-resistant parasites and mosquitoes resistant to insecticides. Early diagnosis and prompt treatment of cases are of extreme importance. The ideal diagnostic method that would be most beneficial for eliminating malaria needs to be rapid, simple to perform, inexpensive, sensitive, accurate and non-invasive.

Currently available diagnostic methods for malaria include the identification of malaria parasites or parasite proteins in blood by microscopy and rapid diagnostic tests (RDT) and parasite DNA by polymerase chain reaction (PCR). Microscopic examination of Giemsa-stained thick blood film is the diagnostic gold standard, but even trained microscopists routinely detect only $50-100$ parasites or more/microlitre of peripheral blood [2, 3], thus missing infected individuals with very low parasitaemia $[4,5]$. People living in low malaria transmission areas harbour submicroscopic parasitaemia [6, 7] and constitute reservoirs that sustain transmission [8]. RDTs detect malaria parasite-specific proteins, such as histidine-rich protein-2 (HRP-2) in plasma. RDTs are easy to perform and suitable for field settings. Although multi-survey analyses show a strong association between prevalence of malaria by RDT and by microscopy [9], RDTs detect more infections than microscopic examination $[2,4,10]$. On the other hand, HRP-2-based RDTs may show falsepositive results for up to a month following parasite clearance [5, 10-12]. Molecular techniques are highly sensitive with PCR detecting as low as 1-5 parasites/ $\mu \mathrm{l}$ of blood [13-16]. Despite differences in their procedures and performances, microscopy, RDT, and nested PCR (nPCR) for malaria diagnosis share a common problem, that is, the requirement of blood samples. Collection of blood is not risk-free. Pain is experienced and phobias linked with finger pricks and needles have been clinically described [17-19]. Also, cultural and religious myths discourage some individuals from providing blood samples. These factors reduce participant compliance in epidemiological surveys where repeated sampling is required. Furthermore, accidental transmission of bloodborne pathogens such as HIV and hepatitis viruses can occur during blood draws and finger-pricks. A better method for malaria diagnosis is needed that incorporates the accuracy of PCR and the use of non-invasive clinical specimens.

Human saliva is readily available and is increasingly being recognized as an important diagnostic specimen. While more than $98 \%$ of human saliva is composed of water [20], the salivary fluid contains many constitutive and infiltrating electrolytes, proteins, and DNA that have been explored for diagnoses and monitoring of a broad variety of diseases [21-23]. For example, molecular markers of malignancy, such as p53 mutations and carcinoembryonic antigen have been detected in saliva of patients with oral carcinomas [24], and saliva concentrations of some biomarkers of cardiovascular disease correlate with corresponding serum concentrations [25]. Also, saliva-based kits have been developed for the diagnosis of HIV [26] and human papilloma virus [27].

In the field of malaria diagnostics, there have been reports of the detection of malaria parasite HRP-2, lactate dehydrogenase and $P$. falciparum DNA in the saliva of infected individuals [28-34]. Although some investigators have also detected malaria parasite DNA in urine samples, the sensitivity of saliva-based detection is significantly higher than urine-based detection of malaria parasite DNA [30-34]. Thus, saliva is a more promising non-blood alternative for malaria diagnosis than urine. The performance of PCR using saliva compared to blood for detecting Plasmodium DNA varies due to differences in experimental and analytic methods used by different laboratories [29-31, 33, 34].

Storage condition of saliva samples from the point of collection can affect DNA stability and PCR sensitivity [30]. In most studies that have investigated saliva as a diagnostic medium for malaria parasites, saliva samples were refrigerated or frozen from the point of collection until DNA extraction [30-34]. While this approach is valid, it is costly to maintain and not feasible in many resource-limited and remote areas. Presently, no study has evaluated the performance of saliva samples collected and stored at room temperature for the diagnosis of malaria. Progress in basic science research has led to the development of kits that can be used to collect and preserve microbial nucleic acid, including the OMNIgene $^{\circledR} \cdot$ ORAL saliva collection and microbial DNA stabilization kit designed to maintain the stability of total DNA in saliva at room temperature [35]. The present study, was aimed at evaluating the performance of saliva-based nested PCR for detecting P. falciparum DNA 
in saliva collected in the OMNIgene ${ }^{\circledR}$. ORAL (OM-501) kit and stored at room temperature for up to 13 months, from suspected malaria patients in Cameroon.

\section{Methods}

\section{Study design and population}

A cross-sectional study was conducted from October 2014 to April 2015 in selected health care facilities in three regions of Cameroon, i.e., the Far North, Centre, and Northwest regions. In the Far North region, the study was conducted in the Maroua regional hospital; the Catholic Health Center Nkolbisson was the study site in the Center region; while the PMI Nkwen Bamenda and the Mother of Mary Hospital Widikum were study sites in the Northwest region. Malaria transmission is perennial in both the Center and North West regions, but peak transmission occurs at different times of the year; whereas, malaria transmission is seasonal in the Far North region. All three regions were selected as part of an on-going study aimed at characterizing the etiologies of non-malarial fevers in Cameroon. Individuals at least 2 years old with axillary temperature above $37.5{ }^{\circ} \mathrm{C}$ at presentation or complaint of fever within $24 \mathrm{~h}$ preceding enrollment were included in the study.

Informed consent was obtained from eligible participants who were above 18 years. Parents or legal guardians of younger children gave written informed assent on behalf of their children. Ethical approvals were obtained from the Committee on Human Subjects of the University of Hawaii (protocol number CHS 21724) and the National Research Ethics Committee of the Ministry of Public Health Cameroon (protocol Number 2014/04/442/CE/CNERSH/SP). Administrative approvals were also obtained from the directors of the various health institutions and from the Ministry of Public Health, Cameroon.

\section{Sample collection and storage}

After informed consent had been obtained, paired blood and saliva samples were collected from each participant. Approximately $2 \mathrm{ml}$ of venous blood was drawn into an EDTA tube. Blood samples were transported in cold boxes to the laboratory where they were aliquoted and stored at $-20{ }^{\circ} \mathrm{C}$ until DNA extraction. Participants were requested to dispense approximately $1 \mathrm{ml}$ of saliva into OMNIgene ${ }^{\circledR}$.ORAL (OM-501) kit (DNA Genotek, Ottawa, Ontario, Canada) following recommendations from the manufacturer. To avoid blood contamination of saliva, individuals with overt gum bleeding or who complained of pain in any part of their mouth were excluded. All saliva samples were stored at room temperature from the time of collection until DNA extraction (about 2-6 weeks). After 12-13 months of storage at room temperature DNA was re-extracted from saliva aliquots of patients who original tested positive for P. falciparum DNA in saliva.

\section{Malaria microscopy}

Thick blood smears were prepared, stained with $10 \%$ Giemsa and read by two trained microscopists. A slide was considered positive if one or more blood-stage malaria parasites was detected after reading at least 100 high power fields. Parasitaemia (parasites/ $\mu \mathrm{l}$ of blood) was determined by counting the number of parasites against 200 white blood cells and multiplying a constant of 8000 white blood cells/ $\mu$ l of blood. Each slide was read by two experienced microscopists and their parasitaemia readings were averaged. Discrepancies greater than $10 \%$ between two readings were resolved by the reading of a third technician.

\section{DNA extraction and nested PCR}

DNA was extracted from $200 \mu \mathrm{l}$ whole blood and $200 \mu \mathrm{l}$ of saliva using NucleoSpin columns (Macherey-Nagel, Duren Germany), following manufacturer's instructions. Purified DNA from each sample was eluted into $100 \mu \mathrm{l}$ of elution buffer and stored at $-20^{\circ} \mathrm{C}$ until nested PCR was conducted, usually within $48 \mathrm{~h}$. The gene target for PCR amplification was the multicopy $18 \mathrm{~s}$ rRNA plasmodial gene using standard protocols [35, 36]. For each sample, a $20 \mu \mathrm{l}$ PCR reaction mix was prepared consisting of $10 \mu \mathrm{l}$ of $2 \times$ GoTaq $^{\circledR}$ Green Master Mix (Promega, Madison USA), $6 \mu$ l of nuclease-free water, $2 \mu \mathrm{l}$ of template DNA and $1 \mu \mathrm{l}$ each of $5 \mu \mathrm{M}$ forward and reverse primers. For the first step of the nested PCR, eluted DNA template and genus-specific forward and reverse primers were used (rPLU5: 5'-CCTGTTGTTGCCTTAAACTTC-3' and rPLU6: $5^{\prime}$-TTAAAATTGTTGCAGTTAAAACG-3'). For second step of the nested PCR, first step nested PCR amplification product was used as template along with $P$. falciparum-specific primers (rFAL1: 5'-TTAAACTGGTTTGGGAAAACCAAATATATT3'and rFAL2: 5'-ACACAATGAACTCAATCATGACTACCCGTC-3') [36, 37]. Purified P. falciparum DNA, extracted DNA from a malaria-naive individuals and molecular grade water were used as positive, negative and no template controls, respectively. Reaction conditions used have been described elsewhere [36, 37]. Nest-2 products were electrophoresed on ethidium bromidestained 2\% agarose gels and visualized on the Gel Doc ${ }^{\mathrm{TM}}$ $\mathrm{XR}+$ System (Bio-Rad, USA). Samples were qualitatively scored as positive or negative if 205-bp bands were present or absent. 


\section{Statistical analysis}

Descriptive analyses were performed with statistical analysis programs for Apple Mac computer (AnalystSoft Inc. version 5) and Graph Pad Prism (version 6). Sensitivity, specificity, positive predictive value (PPV), and negative predictive value (NPV) were used as standard parameters to assess diagnostic performance. The $\kappa$ coefficient was used to estimate agreement on a scale of $0-1$, after correcting for agreement due to chance, between saliva nPCR and microscopy or blood nPCR results. Diagnostic test performance was conducted on MedCalc software (version 16.8). P values $<0.05$ were considered significant. Paired $t$ test was used to compare the differences between DNA concentration in saliva samples when they were initially collected and 12-13 months later. The Mann-Whitney non-parametric test was used to compare initial peripheral parasitaemia of saliva samples that remained positive after 12-13 months at room temperature and saliva samples that were initially positive but became negative after 12-13 months of storage.

\section{Results}

Matched blood and saliva samples were collected from 222 participants living in three different geographical regions of Cameroon (Fig. 1). More females $(\mathrm{n}=158$ [71\%]) than males $(\mathrm{n}=64$ [29\%]) were enrolled in this study. The mean age of the study participants was 22 years (range 2 to 76 years) with age distribution as follows: $2-10$ years $(n=60[27 \%]), 11-20$ years $(n=47$ [21\%]), $21-30$ years $(\mathrm{n}=93[42 \%])$ and $\geq 40$ years

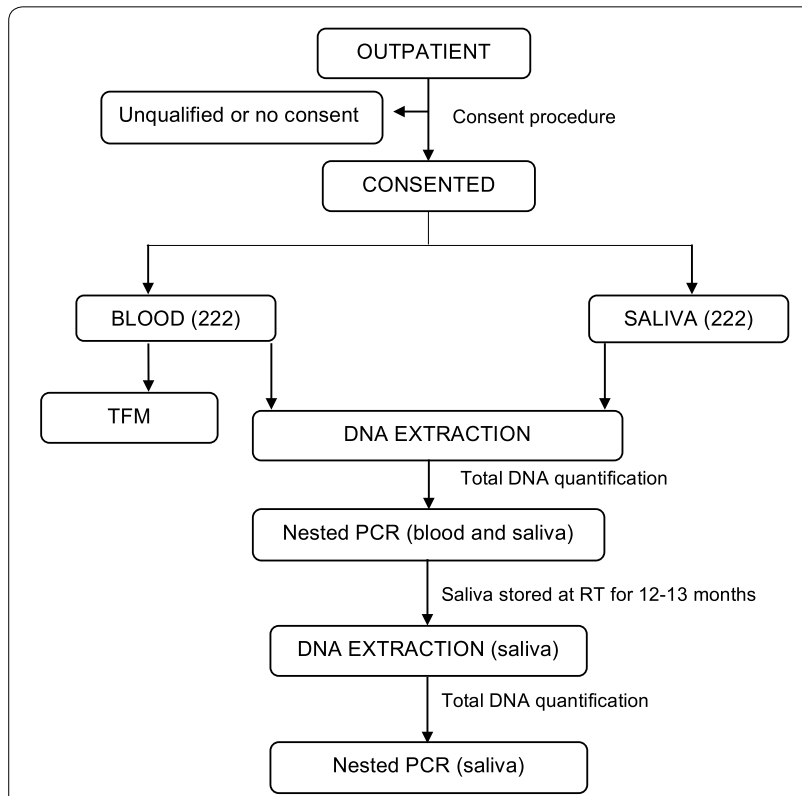

Fig. 1 Study design for enrollment, sample collection and laboratory assays. TFM thick film microscopy; RT room temperature $(\mathrm{n}=22[10 \%])$. The prevalence of malaria by TFM, nPCR-blood, and nPCR-saliva was 24,35 , and $28 \%$, respectively (Table 1$)$. There were $25(32 \%)$ malaria infections detected by nPCR-blood that were slide negative (i.e., submicroscopic infections), while nPCR-saliva identified 13 (20\%) more malaria infections than TFM. The overall agreement of microscopy results between the two technicians was $98 \%$.

To determine the diagnostic test performance of nPCRsaliva and nPCR-blood, TFM was used as the gold standard. All samples that were malaria-positive by microscopy were also identified by nPCR-blood giving a sensitivity of $100 \%$, while nPCR-saliva correctly identified $95 \%$ of microscopy-positive samples giving a sensitivity of $95 \%$. However, the specificity of nPCR-saliva and nPCR-blood were $93 \%$ and $87 \%$ compared to microscopy, respectively. nPCR-saliva and nPCR-blood had a "very good" (kappa 0.8 ) and "good" agreement (kappa 0.7), respectively, with TFM for the diagnosis of malaria (Table 2).

When nPCR-blood was used as the reference standard, the sensitivity of nPCR-saliva was $82 \%$. Moreover, nPCRsaliva had a "very good" agreement (kappa 0.8) with nPCR-blood for diagnosis of malaria (Table 3).

To determine the performance of nPCR-saliva with respect to parasitaemia and age, malaria slide-positive data were stratified into different parasitaemia and age

Table 1 Baseline P. falciparum prevalence by different test methods

\begin{tabular}{llll}
\hline Test method & \multicolumn{2}{l}{ Number of samples } & Prevalence (\%) \\
\cline { 2 - 3 } & Positive & Negative & \\
\hline Thick film microscopy & 53 & 169 & 24 \\
nPCR-blood & 78 & 144 & 35 \\
nPCR-saliva & 66 & 156 & 28 \\
\hline
\end{tabular}

Table 2 Diagnostic test performance of nPCR-saliva and nPCR-blood with thick film microscopy as reference standard in the diagnosis of malaria

\begin{tabular}{lll}
\hline Test characteristics & NPCR-saliva & NPCR-blood \\
\hline Sensitivity $[95 \% \mathrm{Cl}]$ & $95 \%[85$ to 99$]$ & $100 \%[94$ to 100$]$ \\
Specificity $[95 \% \mathrm{Cl}]$ & $93 \%[88$ to 99$]$ & $87 \%[80$ to 91$]$ \\
PPV [95\%Cl] & $83 \%[72$ to 91$]$ & $72 \%[61$ to 82$]$ \\
NPP [95\%Cl] & $98 \%[94$ to 99$]$ & $100 \%[97$ to 100$]$ \\
PLR [95\%Cl] & $14[8$ to 25$]$ & $7[5$ to 11$]$ \\
NLR [95\%Cl] & $0.06[0.02$ to 0.17$]$ & 0 \\
Observed agreements & $94 \%$ & $90 \%$ \\
Kappa value & 0.8 & 0.7
\end{tabular}

PPV positive predictive values, NPP negative predictive values, $P L R$ positive likelihood ratio, NLR, negative likelihood ratio 
Table 3 Diagnostic test performance of nPCR-saliva and thick film microscopy with $\mathrm{nPCR}$-blood as reference standard in the diagnosis of malaria

\begin{tabular}{lll}
\hline Test characteristic & NPCR-saliva & Thick film microscopy \\
\hline Sensitivity [95\%Cl] & $82 \%[72$ to 90$]$ & $68 \%[56$ to 78$]$ \\
Specificity [95\%Cl] & $99 \%[95$ to 100$]$ & $100 \%[97$ to 100$]$ \\
PPV [95\%Cl] & $97 \%[89$ to 99$]$ & $100 \%[93$ to 100$]$ \\
NPV [95\%Cl] & $91 \%[85$ to 95$]$ & $85 \%[79$ to 90$]$ \\
PLR [95\%Cl] & $59 \%[15$ to 235$]$ & \\
NLR [95\%Cl] & $0.2[0.11$ to 0.29$]$ & $0.32[0.23$ to 0.44$]$ \\
Observed agreements & $93 \%$ & $89 \%$ \\
Kappa value & 0.8 & 0.7 \\
\hline
\end{tabular}

PPV, positive predictive values; NPP, negative predictive values; PLR, positive likelihood ratio; NLR, negative likelihood ratio

groups and the sensitivity and specificity calculated for each group. There were three false-negative samples with parasitaemia ranging from $<100$-(one sample) and 1000-2000-parasites/ $\mu$ l of blood (two samples). At parasitaemia $>10,000$ parasites/ $\mu \mathrm{l}$ of blood, the sensitivity and specificity of nPCR-saliva were $100 \%$ each. Meanwhile, the sensitivity of nPCR-saliva was $100 \%$ in the age group $>40$ years (Tables 4 and 5 ).

To determine the stability of total DNA and $P f$ DNA in saliva samples at ambient temperature, samples were stored at room temperature for 12-13 months. Then, total DNA was extracted, quantified and nPCR-saliva repeated using the same reaction conditions as before. There was a significant decrease $(\mathrm{P}<0.0001)$ in the total DNA concentration after 12-13 months (mean $38.7 \mathrm{ng} /$ $\mu \mathrm{l})$ as compared to the total DNA concentration when the samples were collected (mean $68.3 \mathrm{ng} / \mu \mathrm{l}$ ) (Fig. 2). However, $80 \%$ of the saliva samples that were positive for $P f$ DNA at the time of collection remained positive

Table 4 Sensitivity of nPCR-saliva with respect to parasitaemia in the diagnosis of malaria

\begin{tabular}{llllll}
\hline Parasitaemia/ $\boldsymbol{\mu l}$ & $\mathbf{n}$ & \multicolumn{4}{l}{ Test characteristics } \\
\cline { 3 - 6 } & & TP & FN & Sensitivity (\%) & Sensitivity (\%) \\
\hline Submicroscopic & 31 & 20 & 11 & $\mathrm{n} / \mathrm{a}$ & 65 \\
$<1000$ & 7 & 6 & 1 & 86 & 86 \\
$1000-10,000$ & 13 & 11 & 2 & 85 & 85 \\
$>10,000-<50,000$ & 11 & 11 & 0 & 100 & 100 \\
$50,000-<100,000$ & 9 & 9 & 0 & 100 & 100 \\
$>100,000$ & 7 & 7 & 0 & 100 & 100 \\
\hline
\end{tabular}

TP true positive; FN false-negative

a Sensitivity of nPCR-saliva with TFM as reference standard

b Sensitivity of nPCR-saliva with nPCR-blood as reference standard
Table 5 Performance of nPCR-saliva across different age group

\begin{tabular}{lllll}
\hline Test characteristics & \multicolumn{5}{l}{ Age group (years) (n) } \\
\cline { 2 - 5 } & $\mathbf{2 - 1 0 ( 6 0 )}$ & $\mathbf{1 1 - 2 0 ( 4 7 )}$ & $\mathbf{2 1 - 3 9}(\mathbf{9 3})$ & $\mathbf{>} \mathbf{4 0}$ (22) \\
\hline Median parasitaemia/ & 71,907 & 23,257 & 26,760 & 13,600 \\
$\quad$ Hl of blood & & & & \\
Sensitivity (\%) & 94 & 94 & 93 & 100 \\
Specificity (\%) & 88 & 97 & 95 & 100 \\
PPV (\%) & 76 & 89 & 78 & 100 \\
NPV (\%) & 97 & 99 & 99 & 100 \\
\hline
\end{tabular}

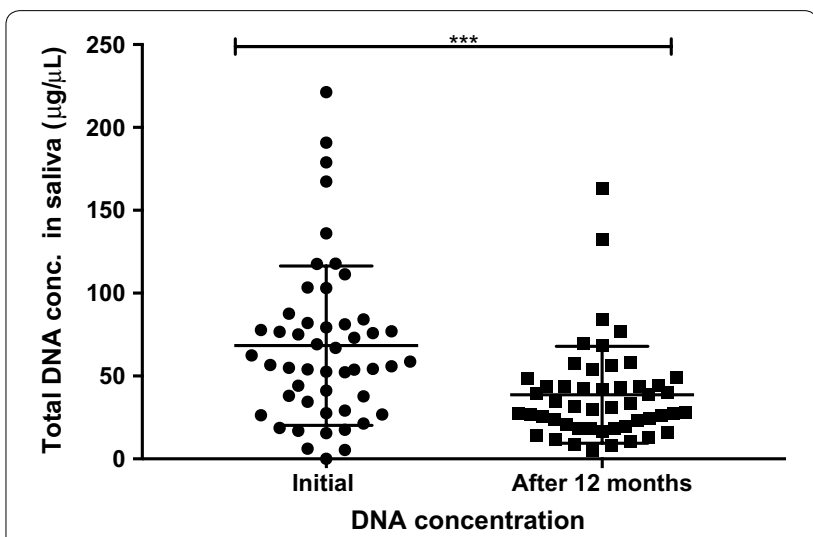

Fig. 2 Comparison of total DNA concentration in Plasmodium falciparum positive saliva samples. DNA was extracted from $200 \mu \mathrm{ll}$ of saliva when they were initially collected and quantified. The saliva samples were left at room temperature for 1 year and DNA was reextracted and quantified. ${ }^{* *} \mathrm{P}=0.0002$

12-13 months later even though the samples were stored at room temperature (Table 6). The initial mean parasitaemia of saliva samples that remained positive after 12-13 months at room temperature was 50,221 parasites/ul of blood while it was 13,540 parasites/ $\mu$ l of blood in saliva samples that were initially positive but became negative 12-13 months later. This difference was statistically significant $(\mathrm{P}=0.0065)$.

\section{Discussion}

Saliva is increasingly being recognized as a potential non-invasive alternative to blood for malaria diagnosis. Sample handling methods that do not compromise the quality of samples and do not require cold chains are ideal for field settings in low and middle-income countries. This study was conducted to assess the diagnostic performance of $\mathrm{nPCR}$ for detection of $P$. falciparum DNA in saliva collected into OMNIgene ${ }^{\circledR}$. ORAL (OM-501) kit and stored at room temperature. Nested PCR-saliva was 
Table 6 Relationship between parasitaemia and nPCR-saliva after one year

\begin{tabular}{lcc}
\hline Parasitaemia at enrolment $(\mathbf{n})$ & $\begin{array}{l}\text { Samples that remained positive } \\
\text { after } \mathbf{1} \text { year } \mathbf{n}(\%)\end{array}$ & $\begin{array}{l}\text { Samples initially positive but } \\
\text { negative after } \mathbf{1} \text { year } \mathbf{n}(\%)\end{array}$ \\
\hline Sub microscopic (14) & $7(50)$ & $7(50)$ \\
$<1000(5)$ & $5(100)$ & 0 \\
$1000-10,000(11)$ & $9(82)$ & $2(18)$ \\
$>10,000-<50,000(11)$ & $11(100)$ & 0 \\
$50,000-<100,000(7)$ & $7(100)$ & 0 \\
$>100,000(6)$ & $5(83)$ & $1(17)$ \\
\hline
\end{tabular}

Originally, 53 samples were $n P C R$-saliva-positive. A year later, the samples were re-screened and $n=43$ remained positive, but 10 were negative

compared with two well-established blood-based methods for malaria diagnosis, i.e., TFM and nPCR-blood. The prevalence of malaria in the study population detected by nPCR-blood (35\%) was higher than prevalence found by TFM (24\%), agreeing with well-known increased sensitivity of nPCR-blood for diagnosis of malaria [4-6, 13-16], and confirming the existence of submicroscopic infections in the population. The number of malariapositive individuals detected by nPCR-saliva (28\%) was greater than that detected by TFM (24\%), but lower than that detected by nPCR-blood (35\%). Interestingly, nPCR-saliva detected 13 more malaria infections than TFM, which is currently the gold standard for malaria diagnosis.

More detailed parameters of diagnostic performance were used to compare nPCR-saliva with TFM and nPCRblood. When TFM was used as gold standard, nPCRsaliva recorded a sensitivity of $95 \%$, missing only three TFM-positive cases. A closer analysis of these three cases revealed that their parasitaemia was among the lowest in the study (i.e., 80, 1400 and 1800 parasites/ $\mu$ l of blood). Even though the mechanism of transfer of parasite DNA from blood to saliva is still unknown, it is plausible that higher amounts of parasite DNA are found in saliva when blood parasite densities are higher. Indeed, the sensitivity of nPCR-saliva decreased to below $100 \%$ only when parasitaemia ranged from 1000 to $10,000 / \mu$ l (Table 4 ). The sensitivity of the assay used in this study (85\%) is similar to the sensitivity reported previously of $85.2 \%$ by Buppan et al. [30] at parasitaemia greater than 5000/ $\mu$ l. Buppan and collaborators stored saliva samples at $4{ }^{\circ} \mathrm{C}$ while saliva samples in this study were left at room temperature in the OMNIgene ${ }^{\circledR}$. ORAL (OM-501) kit. Taken together, the results show that the saliva collection kit successfully preserved parasite DNA in saliva at room temperature and detection of $P$. falciparum DNA in saliva except at the lowest parasitaemia suggests a passive mechanism of transport of $P$. falciparum DNA along a concentration gradient from blood to saliva.

When nPCR-blood was used as gold standard, nPCRsaliva recorded sensitivity and specificity of 82 and 99\%, respectively, again showing that nPCR-saliva is potentially more sensitive than TFM for malaria diagnosis. However, a few samples showed a lack of concordance between nPCR-saliva and nPCR-blood. In the first case, two samples were positive for $P$. falciparum DNA in saliva but negative for DNA in blood. It is known that malaria parasite density fluctuates over a 48-hour period in blood and is not always detectable due to sequestration of infected erythrocytes and the immune response of the infected individual. The two samples may have been collected when parasitaemia was low or undetectable by TFM. Moreover, $P$. falciparum-infected red blood cells in blood circulate through the spleen where they are removed by splenic macrophages leading to clearance of parasites and their products. Saliva contains fewer macrophages than the spleen, and there is no evidence that infected red cells are present in saliva. Thus, $P$. falciparum DNA in blood may be cleared faster than from saliva. Because follow-up samples were not collected from study participants, it was not possible to determine how long parasite DNA in saliva circulates/persists after parasite clearance from the blood. In the second case, there were 14 samples (11 with undetectable parasites by TFM) for which DNA was detected in blood by PCR, but not in saliva. Some reasons can be evoked. Firstly, low parasitaemia as mentioned above may be associated with little or no DNA present in saliva. Secondly, the infections may have been newly acquired such that blood containing infected RBC or parasite DNA may not have circulated long enough through the salivary glands to infiltration of DNA into saliva. Thirdly, parasite sequestration into the deep tissue via adhesion of PfEMP1 to CD36 can reduce the parasite load that transits through to the salivary gland blood vessels. Also, it is possible that infected erythrocytes sequester in the salivary glands through adhesion to CD36 on the salivary glands blood vessels.

It is important to note that although saliva samples were stored at room temperature, the nPCR-saliva performance in this study was slightly better than nPCRsaliva performance in other studies using saliva stored at $4{ }^{\circ} \mathrm{C}$ or $-20{ }^{\circ} \mathrm{C}[34,38]$. This suggests that saliva samples 
collected in the OMNIgene ${ }^{\circledR}$. ORAL (OM-501) kit used in this study and stored at ambient temperature are as reliable as frozen samples.

For the 14 cases for which DNA was positive in blood but negative in saliva, none of the individuals were $>40$ years ( 5 were $2-10$ years, 3 were $11-20$ years, and six were 21-39 years old). This prompted the investigation of any age-related differences in the sensitivity of nPCR-saliva. Moreover, most previous studies have only enrolled individuals aged 10 years and above. Agestratifications showed that the sensitivity of nPCR-saliva ranged from 94 to $100 \%$ (Table 5) confirming that nPCRsaliva can be used in all age groups.

Finally, 1 year after sample collection, $P$. falciparum DNA could still be detected in $80 \%$ of saliva samples that had been stored at room temperature. Even though there was a significant decrease in the total DNA concentration in the saliva samples, only ten samples that were initially positive by nPCR-saliva were negative 1 year later. Of the ten samples, seven had sub-microscopic parasitaemia when collected. Thus, parasite DNA in saliva samples with low or submicroscopic parasitaemia may undergo some degradation. However, low parasitaemia did not seem to be the critical factor because some the samples with submicroscopic parasitaemia remained positive after 1 year. Taken together, the results show that the saliva collection kit used for this study can preserve $P$. falciparum DNA at room temperature for more than 1 year. Therefore, the use of DNA stabilization for the collection of saliva samples may eliminate the need for cold chain or dry ice in transporting samples from the field or shipping samples abroad thereby, reducing cost. The technology described in this study for diagnosis of malaria in resource-limited countries adds on to the armamentarium needed for elimination of malaria.

\section{Conclusions}

The results of this study support the conclusion that nPCR-saliva is more sensitive than TFM for malaria diagnosis, at least in patients with fever. Furthermore, the results demonstrate that $\mathrm{nPCR}$ on saliva collected from individuals of different ages and stored in the OMNIgene $^{\circledR}$. ORAL (OM-501) kit at room temperature are equally, or more accurate than results previouslyreported for nPCR on saliva stored at $4{ }^{\circ} \mathrm{C}$ or $-20{ }^{\circ} \mathrm{C}$. Even after 1 year, $P$. falciparum DNA could still be detected in saliva samples stored at ambient temperature. With the capacity to store Plasmodium DNA at ambient temperature and the non-invasive sample collection procedure, OMNIgene ${ }^{\circledR}$.ORAL, saliva-based nPCR presents a new diagnostic tool for clinical trials and epidemiological surveillance studies where submicroscopic infections need to be detected.

\section{Abbreviations}

HRP-2: histidine-rich protein-2; nPCR: nested PCR; NLR: negative likelihood ratio; NPV: negative predictive value; PCR: polymerase chain reaction; PLR: positive likelihood ratio; PPV: positive predictive value; RDT: rapid diagnostic test; SSA: Sub-Saharan Africa; TFM: thick film microscopy.

\section{Authors' Contributions}

KOM, STY, LFE, RGL designed the study. KOM, STY, BO, JY, CM, JCD collected the samples, and conducted the laboratory studies. KOM, STY, VRN and DWT contributed to data analysis and finalizing the manuscript. RGL, DWT and VRN supervised the study. All authors read and approved the final manuscript.

\section{Author details \\ ${ }^{1}$ Department of Tropical Medicine, Medical Microbiology and Pharmacology, John A. Burns School of Medicine, University of Hawaii at Manoa, 651 Ilalo Street, Honolulu, HI 96813, USA. ${ }^{2}$ Biotechnology Center, University of Yaoundé I, Yaoundé, Cameroon. ${ }^{3}$ National Medical Research Institute, Yaoundé, Cameroon.}

\section{Acknowledgements}

All study participants and Directors of the various healthcare facilities.

\section{Competing interests}

The authors declare they have no competing interests.

\section{Availability of data and materials}

The dataset produced by the current study is available from the corresponding author upon request.

\section{Consent for publication}

Not applicable.

\section{Ethical approval and consent to participate}

Ethical approvals were obtained from the Committee on Human Subjects of the University of Hawaii (Protocol Number CHS 21724) and the National Research Ethics Committee of the Ministry of Public Health Cameroon (Protocol Number 2014/04/442/CE/CNERSH/SP). Administrative approvals were also obtained from the directors of the various health institutions and from the Ministry of Public Health, Cameroon.

\section{Funding}

KOM, STY, LFE were supported by a Grant (D43TW009074) from the Global Infectious Diseases Training Program, Fogarty International Center, NIH. Partial support was provided by a Grant (P30GM11473) from the Centers of Biomedical Research Excellence, National Institute of General Medical Sciences, NIH.

\section{Publisher's Note}

Springer Nature remains neutral with regard to jurisdictional claims in published maps and institutional affiliations.

Received: 24 July 2017 Accepted: 23 October 2017

Published online: 27 October 2017

\section{References}

1. WHO. World Malaria Report 2015. Geneva, World Health Organization. 2015; WHO/HTM/GM:238.

2. Wongsrichanalai C, Barcus MJ, Muth S, Sutamihardja A, Wernsdorfer WH. A review of malaria diagnostic tools: microscopy and rapid diagnostic test (RDT). Am J Trop Med Hyg. 2007;77:119-27.

3. Joanny F, Löhr SJ, Engleitner T, Lell B, Mordmüller B. Limit of blank and limit of detection of Plasmodium falciparum thick blood smear microscopy in a routine setting in Central Africa. Malar J. 2014;13:234.

4. Nankabirwa JI, Yeka A, Arinaitwe E, Kigozi R, Drakeley C, Kamya MR, et al. Estimating malaria parasite prevalence from community surveys in Uganda: a comparison of microscopy, rapid diagnostic tests and polymerase chain reaction. Malar J. 2015:14:528. 
5. Wu L, van den Hoogen LL, Slater H, Walker PGT, Ghani AC, Drakeley CJ, et al. Comparison of diagnostics for the detection of asymptomatic Plasmodium falciparum infections to inform control and elimination strategies. Nature. 2015;528:586-93.

6. Okell LC, Ghani AC, Lyons E, Drakeley CJ. Submicroscopic infection in Plasmodium falciparum-endemic populations: a systematic review and meta-analysis. J Infect Dis. 2009;200:1509-17.

7. Lin JT, Saunders DL, Meshnick SR. The role of submicroscopic parasitemia in malaria transmission: what is the evidence? Trends Parasitol. 2014;30:183-90.

8. Karl S, Gurarie D, Zimmerman PA, King CH, St. Pierre TG, Davis TME. A submicroscopic gametocyte reservoir can sustain malaria transmission. PLoS ONE. 2011;6:e20805.

9. Mappin B, Dalrymple U, Cameron E, Bhatt S, Weiss DJ, Gething PW. Standardizing Plasmodium falciparum infection prevalence measured via microscopy versus rapid diagnostic test. Malar J. 2015;14:460

10. Bell DR, Wilson DW, Martin LB. False-positive results of a Plasmodium falciparum histidine-rich protein 2-detecting malaria rapid diagnostic test due to high sensitivity in a community with fluctuating low parasite density. Am J Trop Med Hyg. 2005:73:199-203.

11. Mouatcho JC, Dean Goldring JP. Malaria rapid diagnostic tests: challenges and prospects. J Med Microbiol. 2013;62:1491-505.

12. Iqbal J, Siddique A, Jameel M, Hira PR. Persistent histidine-rich protein 2, parasite lactate dehydrogenase, and panmalarial antigen reactivity after clearance of Plasmodium falciparum monoinfection. J Clin Microbiol. 2004;42:4237-41.

13. Golassa L, Enweji N, Erko B, Aseffa A, Swedberg G. Detection of a substantial number of sub-microscopic Plasmodium falciparum infections by polymerase chain reaction: a potential threat to malaria control and diagnosis in Ethiopia. Malar J. 2013;12:352.

14. Satoguina J, Walther B, Drakeley C, Nwakanma D, Oriero EC, Correa S, et al. Comparison of surveillance methods applied to a situation of low malaria prevalence at rural sites in the Gambia and Guinea Bissau. Malar J. 2009;8:274.

15. Morassin B, Fabre R, Berry A, Magnaval JF. One year's experience with the polymerase chain reaction as a routine method for the diagnosis of imported malaria. Am J Trop Med Hyg. 2002;66:503-8.

16. Tangpukdee N, Duangdee C, Wilairatana P, Krudsood S. Malaria diagnosis: a brief review. Korean J Parasitol. 2009;47:93-102.

17. Hamilton JG. Needle phobia: a neglected diagnosis. J Fam Pract. 1995:41:169-75.

18. Wright S, Yelland M, Heathcote K, Ng S-K, Wright G. Fear of needles-nature and prevalence in general practice. Aust Fam Physician. 2009;38:172-6.

19. Bienvenu OJ, Eaton WW. The epidemiology of blood-injection-injury phobia. Psychol Med. 1998;28:1129-36.

20. Humphrey SP, Williamson RT. A review of saliva: normal composition, flow, and function. J Prosthet Dent. 2001;85:162-9.

21. Pink R, Simek J, Vondrakova J, Faber E, Michl P, Pazdera J, et al. Saliva as a diagnostic medium. Biomed Pap Med Fac Univ Palacky Olomouc Czech Repub. J Cont Educ Topics Issues. 2009;153:103-10.

22. Malamud D. Saliva as a diagnostic fluid. Dent Clin North Am. 2011;55:159-78

23. Pfaffe T, Cooper-White J, Beyerlein P, Kostner K, Punyadeera C. Diagnostic potential of saliva: current state and future applications. Clin Chem. 2011;57:675-87.
24. Markopoulos AK, Michailidou EZ, Tzimagiorgis G. Salivary markers for oral cancer detection. Open Dent J. 2010;4:172-8.

25. Foley JD, Sneed JD, Steinhubl SR, Kolasa J, Ebersole JL, Lin Y, et al. Oral fluids that detect cardiovascular disease biomarkers. Oral Surg Oral Med Oral Pathol Oral Radiol. 2012;114:207-14.

26. Zachary D, Mwenge L, Muyoyeta M, Shanaube K, Schaap A, Bond V, et al. Field comparison of OraQuick ADVANCE rapid HIV-1/2 antibody test and two blood-based rapid HIV antibody tests in Zambia. BMC Infect Dis. 2012;12:183.

27. SahebJamee M, Boorghani M, Ghaffari S-R, AtarbashiMoghadam F, Keyhani A. Human papillomavirus in saliva of patients with oral squamous cell carcinoma. Med Oral Patol Oral Cir Bucal. 2009;14:e525-8.

28. Wilson NO, Adjei AA, Anderson W, Baidoo S, Stiles JK. Detection of Plasmodium falciparum histidine-rich protein II in saliva of malaria patients. Am J Trop Med Hyg. 2008;78:733-5.

29. Gbotosho GO, Happi CT, Folarin O, Keyamo O, Sowunmi A, Oduola AMJ. Rapid detection of lactate dehydrogenase and genotyping of Plasmodium falciparum in saliva of children with acute uncomplicated malaria. Am J Trop Med Hyg. 2010;83:496-501.

30. Buppan P, Putaporntip C, Pattanawong U, Seethamchai S, Jongwutiwes S. Comparative detection of Plasmodium vivax and Plasmodium falciparum DNA in saliva and urine samples from symptomatic malaria patients in a low endemic area. Malar J. 2010;9:72.

31. Putaporntip C, Buppan P, Jongwutiwes S. Improved performance with saliva and urine as alternative DNA sources for malaria diagnosis by mitochondrial DNA-based PCR assays. Clin Microbiol Infect. 2011;17:1484-91.

32. Ghayour Najafabadi Z, Oormazdi H, Akhlaghi L, Meamar AR, Nateghpour M, Farivar L, et al. Detection of Plasmodium vivax and Plasmodium falciparum DNA in human saliva and urine: loop-mediated isothermal amplification for malaria diagnosis. Acta Trop. 2014;136:44-9.

33. Mharakurwa S, Simoloka C, Thuma PE, Shiff CJ, Sullivan DJ. PCR detection of Plasmodium falciparum in human urine and saliva samples. Malar J. 2006:5:103.

34. Nwakanma DC, Gomez-Escobar N, Walther M, Crozier S, Dubovsky F, Malkin E, et al. Quantitative detection of Plasmodium falciparum DNA in saliva, blood, and urine. J Infect Dis. 2009;199:1567-74

35. Iwasiow RM, Desbois A, Birnboim HC. Long-term stability of DNA from saliva samples stored in the Oragene self-collection kit. Oragene. 2011;3:1-2.

36. Snounou G, Viriyakosol S, Jarra W, Thaithong S, Brown KN. Identification of the four human malaria parasite species in field samples by the polymerase chain reaction and detection of a high prevalence of mixed infections. Mol Biochem Parasitol. 1993;58:283-92.

37. Walker-Abbey A, Djokam RRT, Eno A, Leke RFG, Titanji VPK, Fogako J, et al. Malaria in pregnant Cameroonian women: the effect of age and gravidity on submicroscopic and mixed-species infections and multiple parasite genotypes. Am J Trop Med Hyg. 2005;72:229-35.

38. Pooe OJ, Shonhai A, Mharakurwa S. A PCR screen for malaria carrier infections using human saliva samples. African J Microbiol Res. 2011;5:5120-6.

\section{Submit your next manuscript to BioMed Central and we will help you at every step:}

- We accept pre-submission inquiries

- Our selector tool helps you to find the most relevant journal

- We provide round the clock customer support

- Convenient online submission

- Thorough peer review

- Inclusion in PubMed and all major indexing services

- Maximum visibility for your research

Submit your manuscript at www.biomedcentral.com/submit
BioMed Central 